\title{
Aeollanthus Pubescens Benth Leaf Essential Oil: Its Chemical Composition and the Insecticidal Activity Against the Malaria Vector Anopheles Gambiae (Diptera: Culicidae)
}

\author{
Roméo Barnabé BOHOUNTON \\ University of Abomey-Calavi: Universite d'Abomey-Calavi \\ Luc Djogbenou ( $\square$ Idjogbenou22002@yahoo.fr) \\ University of Abomey Calavi \\ Oswald Yédjinnavênan Djihinto \\ Université d'Abomey-Calavi: Universite d'Abomey-Calavi \\ Oronce Sedjro-Ludolphe Dedome \\ University of Abomey-Calavi: Universite d'Abomey-Calavi \\ Pierre Marie Sovegnon \\ University of Abomey-Calavi: Universite d'Abomey-Calavi \\ Bruno Barea \\ CIRAD Centre de Montpellier: CIRAD Montpellier-Occitanie \\ Aristide Adomou \\ Université d'Abomey-Calavi: Universite d'Abomey-Calavi \\ Pierre Villeneuve \\ CIRAD Centre de Montpellier: CIRAD Montpellier-Occitanie \\ Fidèle Paul Tchobo \\ Université d'Abomey-Calavi: Universite d'Abomey-Calavi
}

\section{Research}

Keywords: Aeollanthus pubescens, Anopheles gambiae, essential oil, bioinsecticidal activity

Posted Date: May 27th, 2021

DOI: https://doi.org/10.21203/rs.3.rs-530977/v1

License: (c) (i) This work is licensed under a Creative Commons Attribution 4.0 International License. Read Full License 


\section{Abstract}

Background: The use of synthetic insecticides is responsible for many cases of resistance in insects. Therefore, the use of natural molecules of ecological interest with insecticidal properties turns out to be an alternative approach to the use of synthetic insecticides. This study aims at investigating the larvicidal, adulticidal activity and the chemical composition of the essential oil of Aeollanthus pubescens Benth on the major malaria vector Anopheles gambiae.

The leaves of Aeollanthus pubescens were collected in the South of the Republic of Benin.

Methods: Three reference strains of Anopheles gambiae s.s. such as Kisumu, Kiskdr and Acerkis were used. The standard WHO guideline for larvicides evaluation was used and the chemical composition of the essential oil was analysed by gas chromatography coupled to mass spectrometry. Adult mosquitoes were exposed to the fragment nets coated with the essential oil for 3 min. Probit regression analysis was used for $\mathrm{LC}_{50}, \mathrm{LC}_{95}, \mathrm{KDT}_{50}$, and $\mathrm{KDT}_{95}$ calculations. The difference between the mortality-dose regressions for the different strains was analysed using the likelihood ratio test (LRT). The Log-rank test was performed to evaluate the difference in survival between the strains.

Results: Fourteen components were identified representing $98.31 \%$ of the total of oil. The major components were carvacrol (51.06

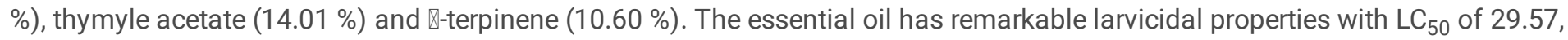
22.95, and $28.37 \mathrm{ppm}$ respectively on Kisumu, Acerkis and Kiskdr strains. With the fragment net treated at $165 \mu \mathrm{g} / \mathrm{cm}^{2}$, the KDT 50 of both Acerkis (1.71 s, $p<0.001)$ and Kiskdr $(2.67 \mathrm{~s}, p<0.001)$ individuals were significantly lower than that of Kisumu (3.77 s). The lifespan of the three mosquito strains decreased respectively to one day for Kisumu $(p<0.001)$, two days for Acerkis $(p<$ $0.001)$ and three days for Kiskdr $(p<0.001)$ compared to their control.

Conclusion: Our findings show that the Aeollanthus pubescens essential oil is an efficient larvicide and adulticide against malaria vector Anopheles gambiae. This bioinsecticidal activity is a promising discovery for the control of the resistant malaria-transmitting vectors.

\section{Introduction}

Vector-borne diseases remain the major causes of death in many tropical countries. The most important vector-borne diseases are malaria, lymphatic filariasis, dengue fever and yellow fever; the pathogens responsible for these diseases are transmitted by the mosquitoes (Diptera: Culicidae) [1, 2]. Among the mosquito-borne infectious diseases, malaria is the most dreadful and the major public health concern in terms of the number of incidence, prevalence, morbidity and mortality in low-income countries of Africa, Asia, Latin America and beyond [3,4]. Despite the national malaria control programmes efforts, nearly $85 \%$ of malaria deaths occurred in 21 sub-Saharan African countries including the Republic of Benin [4]. Malaria is transmitted by the bites of parasiteinfected Anopheles female mosquitoes [5].

So far, most malaria control programs have mainly relied on Artemisinin-based Combination Therapies (ACTs) for the treatment of diagnosed patients and the use of chemical compounds through Insecticides Treated Nets (ITNs) and Indoor Residual Spraying (IRS) for the prevention of human-vector contacts [6]. Nowadays, 14 insecticides belonging to four major classes of synthetic chemical insecticides are recommended by WHO Pesticide Evaluation Scheme (WHOPES) for IRS [7] and four insecticides, all from the pyrethroids group, are recommended for ITNs [8]. However, the overuse of these synthetic chemical insecticides has led to the emergence of resistant malaria vectors; and the frequency of insecticide resistance is widespread especially in African regions [9, 10]. Also, these synthetic insecticides have been recognized to have adverse effects on non-targeted species and affect animal and plant biodiversity [11-13]. The indiscriminate use of these chemicals has also been shown to have severe effects on the environment and impacts on human health [14].

These facts combined with multidrug-resistance in malaria parasite [15] and the absence of an effective vaccine led scientists to focus on searching for environmentally-friendly vector control alternatives with the aim of decreasing the selection pressure for insecticide resistance [16]. This kind of eco-friendly vector control alternatives could be achieved especially with insecticide from botanical sources. Indeed, they are potentially safer for human and the environment and have a minimal residual effect. They are more target-specific; less toxic to vertebrates, and more sustainable than their synthetic counterparts $[17,18]$. 
Beninese traditional medicine and pharmacopoeia medications are richly bio-diversified, which could be a great source for natural insecticides for malaria control [19]. Therefore, it appeared of interest to learn more about Beninese flora for its insecticidal activities. However, to our knowledge, only few studies have been conducted regarding the mosquitocidal activity of the extracts from Beninese plants species [20-22].

Aeollanthus pubescens (A. pubescens) Benth (common name in Benin: Iko) is an annual herbaceous plant belonging to Lamiaceae family anddistributed in many West African countries as well as in Benin [23]. It is commonly used by local populations as food and medicine $[24,25]$. The current study aims at determining the insecticidal potential of $A$. pubescens Benth leaf essential oil against the Afrotropical malaria vector Anopheles gambiae under laboratory conditions in seeking safer alternatives to the existing synthetic insecticides.

\section{Material And Methods}

\section{Plant material and extraction}

The leaves of $A$. pubescens Benth (Fig 1) were collected in July 2014 at Covè $7^{\circ} 28^{\prime} 25.2^{\prime \prime} \mathrm{N}$ latitude; $2^{\circ} 19^{\prime} 13.0^{\prime \prime} \mathrm{E}$ longitude) in Benin and authenticated at the National Herbarium of University of Abomey-Calavi (UAC) where it was kept under voucher AAC 188/HNB.

The leaves were shade dried at $25^{\circ} \mathrm{C} \pm 2^{\circ} \mathrm{C}$ for 72 hours. Three batches of $200 \mathrm{~g}$ of dried leaves were submitted to hydro-distillation in Clevenger apparatus at $100^{\circ} \mathrm{C}$ for 2 hours. The distilled oil was dried using anhydrous sodium sulphate and transferred into an airtight amber-coloured vial and stored at $4{ }^{\circ} \mathrm{C}$ until further use. The yields were averaged over the three experiments of the plant materials.

\section{Chemical analysis of the essential oil of $A$. pubescens leaves.}

\section{Analysis by gas chromatography coupled with flame ionization detection (GC-FID)}

The essential oil constituents were analysed by a capillary GC-FID equipped with a Supelco SPB- 1 column (30 m×0.32 mm i.d, 0.25 $\mu \mathrm{m}$ film thickness). One $\mu \mathrm{L}$ of the essential oil diluted in chloroform were directly injected into the $\mathrm{GC}$. Helium was used as carrier gas with the flow rate of $6 \mathrm{~mL} / \mathrm{min}$ and the splitting ratio of $1 / 17$. The inlet temperature was $250{ }^{\circ} \mathrm{C} / \mathrm{min}, 200-310^{\circ} \mathrm{C}$ at $20^{\circ} \mathrm{C} / \mathrm{min}$, and then maintained at $310{ }^{\circ} \mathrm{C}$ for $2 \mathrm{~min}$.

A capillary GC-MS was used on a TR-1MS column ( $30 \mathrm{~m} \times 0.25 \mathrm{~mm}$ i.d., $0.25 \mu \mathrm{m}$ film thickness). An electron impact was used with ionization energy of $70 \mathrm{eV}$. Helium was used as the carrier gas at a flow rate of $0.6 \mathrm{~mL} / \mathrm{min}$, and the splitting ratio $1 / 17$. The temperature settings were as follows: $70-200{ }^{\circ} \mathrm{C}$ at $10{ }^{\circ} \mathrm{C} / \mathrm{min}, 200-300{ }^{\circ} \mathrm{C}$ at $20^{\circ} \mathrm{C} / \mathrm{min}$, and then maintained at $300^{\circ} \mathrm{C}$ for $1 \mathrm{~min}$. Inlet and MS transfer line temperatures were set at 250 and $320^{\circ} \mathrm{C}$, respectively. All apparatus and accessories were from Thermo Scientific (Courtaboeuf, France) and software controlled data processing (Chromocard and XCalibur). The identification of the essential oil constituents was based on the comparison of their retention times and their Kovats retention indexes relative to $\left(\mathrm{C}_{8}{ }^{-}\right.$ $\mathrm{C}_{20}$ ) n-alkanes. Whenever possible, identifications were based on mass spectra of the authentic standard compounds. Otherwise, identifications were performed using published data [26] and comparison with the NIST mass spectral library.

\section{Mosquito strains}

Three Anopheles gambiae s.s (An. gambiae) laboratory strains that were regulary maintained at the insectarium of the laboratory of Vector-Borne Infectious Diseases at the Institut Régional de Santé Publique Alfred Quenum (IRSP-AQ) of the University of Abomey-Calavi in Ouidah (Benin) were used in this study. Kisumu strain originating from Kenya is a reference strain susceptible to all insecticides [27]. Acerkis strain, which is resistant towards both organophosphate and carbamate based insecticides and is homozygous for (G119S) mutation [28]. Kiskdr strain, which is homozygous for $k d r^{R}$ allele (L1014F) that confers resistance to pyrethroids and DDT [29]. Both AcerKis and Kiskdr strains were supposed to share the same genetic background as the Kisumu strain but differ by the presence of resistance alleles.

The colonies of the three strains were maintained at the insectarium under optimum conditions $\left(25-27^{\circ} \mathrm{C}\right.$ temperature and $70-80 \%$ relative humidity). The third instar larvae, as well as adult females of 3-5 days old of each mosquito strains were used for the 
bioassays.

\section{Bioassays}

\section{Larval bioassay}

The larvicidal properties of the essential oil were conducted according to the standard method recommended by the World Health Organization [30] with slight modifications. Since the essential oil does not dissolve in water, six different concentrations (1000, $2000,3000,4000$ and $5000 \mathrm{ppm}$ ) of the essential oil were prepared in ethanol $96 \%$. Twenty-five third instar larvae of each strain were gently transferred into a plastic beaker containing $99 \mathrm{~mL}$ of water and $1 \mathrm{~mL}$ of each prepared concentration was added to obtain test solutions of 10,20,30, 40 and $50 \mathrm{ppm}$. During bioassays test, larvae were exposed for 24 hours at $26 \pm 2^{\circ} \mathrm{C}$ (temperature measured using Waranet kit (Waranet Solutions SAS, Auch, France)) without any food. After exposure, the larval mortality was recorded. Larvae were considered dead when they were not able to move or swim actively when touched. For each strain, four replicates were performed for a total of 100 larvae per concentration. The control group consisted of batches of larvae exposed to water and the solvent alone (ethanol). In total, three different experiments were conducted on three different days.

\section{Adult Bioassay}

\section{Impregnation of mosquito nets with the essential oil}

Fragments of insecticide free net $\left(13 \mathrm{~cm} \times 13 \mathrm{~cm} ; 169 \mathrm{~cm}^{2}\right)$ were coated with the essential oil.

The masses of essential oil proportional to the net area $\left(169 \mathrm{~cm}^{2}\right)$ per concentration were determined: $9.3,18.6$ and $27.9 \mathrm{mg}$ for the impregnation at 55,110 and $165 \mu \mathrm{g} / \mathrm{cm}^{2}$ respectively after preliminary doses screening. A volume of $1.5 \mathrm{~mL}$ of ethanol HPLC grade was poured into a Petri dish containing the mass of essential oil corresponding to a given concentration. After complete dissolution, the fragment of the mosquito net was coated with the mixture. The impregnated fragment nets were left to dry at room temperature for 5 minutes to allow the essential oil to adhere to the mosquito net and to completely evaporate the ethanol. After drying, treated fragment nets were maintained in the dark to prevent likely reactions of the essential oil constituents with the light and were stored at $4^{\circ} \mathrm{C}$ for 2 to 4 hours, time to perform the cone tests. All coated fragment nets used during the day were treated in the morning at the same time. Different coated fragment nets were used in each replicate to avoid the essential oil concentration loss. The nets of the same size were also treated with $1.5 \mathrm{~mL}$ of ethanol and was used as control.

\section{Cone test}

The cone test was used to assess the adulticidal activity of the essential oil on the adult mosquitoes. The cone test is an adaptation of the WHO cone bioassay [31], with the following modification: During the assay, the test operator holds a forearm behind the cone to provide a host for attraction (Fig 2).

Unfed 3-5 days old female mosquitoes of Kisumu, Acerkis and Kiskdr strains were used in the test. On the day of testing, female were starved for 4 hours before testing. Groups of five female mosquitoes were placed into plastic cups and moved into the testing room one hour before testing begins to allow the mosquitoes to acclimatise to room conditions. The fragment nets for test or control were placed over a dedicated hole on the Perspex boards and secured using a clear tape. A second Perspex board was laid on the first board creating a test/control net "sandwich" between the two boards. The cone was placed over the net and plugged above with a piece of parafilm. A batch of 5 mosquitoes was transferred into the cone with the operator's forearm in position. Mosquitoes were then exposed to the fragments for three minutes. Ten replicates of batches of 5 mosquitoes of each strain were run per concentration of impregnated nets.

\section{Monitoring of the lethal effect of mosquito exposure to the essential oil.}

After exposure, mosquitoes were removed from the cone, transferred into a recovery cups and provided with $10 \%$ of honey solution soaked on a cotton pad. Mosquito knockdown was recorded at 60 minutes post-test. Mosquito mortality was then recorded every day until the death of the last female of each mosquito strain.

\section{Data analysis}


The analysis of dose-mortality responses in larval bioassays was performed using the BioRssay script version 6.2 [32] in $\mathrm{R}$ software Version 3.0 [33]. This script calculates the mortality-dose regression using a generalized linear model (GLM). To assess the adequacy of the model, a chi-square test between the observed dead numbers (data) and the dead numbers predicted by the regression is used. It also tests whether the mortality-dose regressions are similar for the different strains, using a likelihood ratio test (LRT). If there are more than two strains test, it also computes the pairwise test, and corrects it using sequential Bonferroni correction (Hommel, 1988). Finally it computes the lethal concentrations inducing 50\% ( $\left.\mathrm{LC}_{50}\right)$ and $95 \%\left(\mathrm{LC}_{95}\right)$ mortality recorded in each strain and the associated confidence intervals; the resistance ratios, i.e. $\mathrm{RR}_{50}$ or $\mathrm{RR}_{95}\left(\mathrm{LC}_{50}\right.$ or $\mathrm{LC}_{95}$ in each strain divided respectively by the $\mathrm{LC}_{50}$ or $\mathrm{LC}_{95}$ of the reference strain) and their $95 \%$ confidence intervals. Susceptible or resistant status was defined according to Mazzarri \& Georghiou [34] and Bisset et al. [35] criteria : $\mathrm{RR}_{50} \leq 1$ indicates susceptibility to the tested insecticide, while $\mathrm{RR}_{50}>1$ indicates insecticide resistance. For resistance levels, three categories were ranked as follow: low resistance for $R_{50}<5$, moderate resistance for $5 \leq R R_{50} \leq 10$ and high resistance for $R_{50}>10$ [34,35]. The times at which $50 \%$ or $95 \%$ of mosquitoes fell on their back or their side, i.e. knockdown time $\left(\mathrm{KDT}_{50}\right.$ or KDT $\left._{95}\right)$ and their $95 \%$ confidence intervals were estimated after probit regression in R software using the package 'ecotox' [36] based on the method described by Finney [37], the difference between two $\mathrm{KDT}_{50} s$ was tested using the ratio test developed in Wheeler et al. 2006 [38]. The mosquito survival after exposure to the essential oil impregnated net was analysed by Kaplan-Meier survival curves using GraphPad Prism 8.0.2 software (San Diego, California USA). The Log-rank test was performed to evaluate the difference in survival between the strains. All statistical analyses were set at a significance threshold of $p \otimes 0.001$.

\section{Results}

\section{Chemical composition of $A$. pubescens leaf essential oil}

The percentage yields of essential oil obtained from the hydro-distillation of the leaves of $A$. pubescens was $0.30 \pm 0.02 \%$ (w/w based on fresh leaves; mean $\pm \mathrm{SE}$ ). From the chemical composition of the essential oil of $A$. pubescens (Table 1), fourteen compounds were identified, accounting for $98.31 \%$ of the crude essential oil's mass. The essential oil of $A$. pubescens aerial part had higher oxygenated monoterpenes (60.4\%) than monoterpene hydrocarbons (22.39\%) and sesquiterpene hydrocarbons (15.52\%) (Table 1). The major component of the essential oil was carvacrol (51.06\%), followed by other components thymol

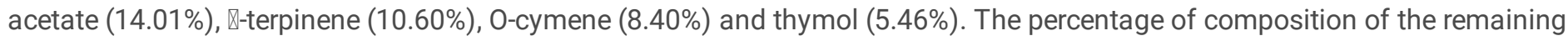
nine compounds ranged from 0.19 to $2.02 \%$ (Table 1 ).

Table 1: Chemical composition of the Aeollanthus pubescens Benth essential oil. 


\begin{tabular}{|llll|}
\hline Peak No & RI & Components & Peak area (\%) \\
\hline $\mathbf{1}$ & 940 & a-Pinene & 0.58 \\
\hline $\mathbf{3}$ & 986 & Myrcene & 2.02 \\
\hline $\mathbf{4}$ & 1005 & Lumicolchicine & 0.19 \\
\hline $\mathbf{5}$ & 1020 & o-Cymene & 8.40 \\
\hline $\mathbf{6}$ & 1031 & 1,8-cineole & 0.60 \\
\hline $\mathbf{7}$ & 1057 & Y-Terpinene & 10.60 \\
\hline $\mathbf{9}$ & 1088 & Linalool & 0.88 \\
\hline $\mathbf{1 0}$ & 1162 & Borneol & 1.40 \\
\hline $\mathbf{1 1}$ & 1173 & Terpin-4-ol & 1.60 \\
\hline $\mathbf{1 2}$ & 1284 & Thymol & 5.46 \\
\hline $\mathbf{1 3}$ & 1359 & Thymol acetate & 51.06 \\
\hline $\mathbf{1 4}$ & 1488 & B-Cubebene & 14.01 \\
& & Acid [(2,4,6-triethylbenzoyl) thio] acetic & 1.26 \\
\hline & & Total identified (\%) & 0.24 \\
\hline & & Sesquiterpenes hydrocarbons & 15.52 \\
\hline & & Monoterpenes hydrocarbons & 22.39 \\
\hline & & & 60.4 \\
\hline
\end{tabular}

Rl: relative retention indices as determined on an HP-1 column using the homologous series of n-alkanes.

\section{Toxicity of $A$. pubescens essential oil on Anopheles gambiae s.s larvae}

Larval bioassay conducted on A. gambiae strains larvae showed considerable larvicidal activity of $A$. pubescens essential oil with $\mathrm{LC}_{50}$ values of 22.95, 28.52 and 29.57 ppm respectively for Acerkis, Kiskdr and Kisumu strains (Table 2). No mortality was recorded in the control batches of each strain treated with ethanol. The chi-square test between the observed dead numbers (data) and the dead numbers predicted by the log-dose probit-mortality regression indicated that the data were well fitted by a straight line (Table 2). Acerkis and Kiskdr strains were both susceptible to the essential oil with lower $R_{50}$ values ( 0.78 and 0.96 for Acerkis and Kiskdr strain respectively; Table 2). The Likely ratio test showed that Acerkis strain larvae $\left(\mathrm{LC}_{50}=22.95 \mathrm{ppm}\right)$ were significantly more susceptible to the essential oil compared to $\operatorname{Kiskdr}\left(\mathrm{LC}_{50}=28.52 \mathrm{ppm}, p<0.001\right)$ and Kisumu larvae $\left(\mathrm{LC}_{50}=29.57 \mathrm{ppm}, p<0.001\right)$ (Table 2). However, Kisumu and Kiskdr larvae susceptibility was not significantly different $(p=0.41)$.

Table 2: Toxicity of $A$. pubescens against Anopheles gambiae larvae after $24 \mathrm{~h}$ exposure. 


\begin{tabular}{|c|c|c|c|c|c|c|c|c|c|}
\hline $\begin{array}{l}\text { Mosquito } \\
\text { strains }\end{array}$ & $\begin{array}{l}\mathrm{LC}_{50} \\
(\mathrm{ppm})\end{array}$ & 95\% C.I & $\mathrm{RR}_{50}$ & $\begin{array}{l}95 \% \mathrm{Cl} \\
\text { [LCL- } \\
\text { UCL] }\end{array}$ & $\begin{array}{l}\mathrm{LC}_{95} \\
(\mathrm{ppm})\end{array}$ & $\begin{array}{l}95 \% \mathrm{Cl} \\
\text { [LCL-UCL] }\end{array}$ & $\begin{array}{l}\text { Slope } \\
\pm \text { S.E }\end{array}$ & $\begin{array}{l}\text { Intercept } \\
\pm \text { S.E }\end{array}$ & $\begin{array}{l}\text { Chi(p) } \\
\text { value }\end{array}$ \\
\hline Kisumu & 29.57 & $\begin{array}{l}28.58- \\
30.54\end{array}$ & - & - & 49.94 & $\begin{array}{l}47.36- \\
53.20\end{array}$ & $\begin{array}{l}7.23 \pm \\
0.35\end{array}$ & $\begin{array}{l}-10.63 \\
0.53\end{array}$ & 0.96 \\
\hline Acerkis & 22.95 & $\begin{array}{l}20.97- \\
24.89\end{array}$ & 0.78 & $\begin{array}{l}0.63- \\
0.96\end{array}$ & 52.26 & $\begin{array}{l}46.12- \\
61.80\end{array}$ & $\begin{array}{l}4.60 \pm \\
0.37\end{array}$ & $\begin{array}{l}-6.26 \\
0.53\end{array}$ & 0.26 \\
\hline Kiskdr & 28.52 & $\begin{array}{l}27.07- \\
29.93\end{array}$ & 0.96 & $\begin{array}{l}0.79- \\
1.19\end{array}$ & 49.73 & $\begin{array}{l}46.06- \\
54.89\end{array}$ & $\begin{array}{l}6.81 \pm \\
0.51\end{array}$ & $\begin{array}{l}-9.91 \\
0.71\end{array}$ & 0.14 \\
\hline
\end{tabular}

LC $_{50 / 95}$ : lethal concentrations; S.E: standard error; C.I: Confidence interval; $\mathbf{R R}_{50}$ is resistance ratio at LC ${ }_{50}:$ LC $_{50}$ (resistant strain)/ LC $_{50}$ (Kisumu). LCL: Lower confidence limit; UCL: Upper confidence limit

Chi(p) is indicated to judge whether the data are well fitted to the regression or not. The fits are acceptable when the $p$-value is over 0.05 .

\section{Adulticidal activity of $A$. pubescens essential oil against Anopheles gambiae strains}

\section{Knockdown time}

The average time estimated for knockdown 50\% $\left(\mathrm{KDT}_{50}\right)$ or $95 \%\left(\mathrm{KDT}_{95}\right)$ of adult An. gambiae females of each strain decreased with the increasing treatment concentration. The $\mathrm{KDT}_{50}$ was less than 4 seconds for all mosquito strains in contact with fragment net treated at $165 \mu \mathrm{g} / \mathrm{cm}^{2}$ (3.77 s for Kisumu; $1.71 \mathrm{~s}$ for Acerkis and $2.67 \mathrm{~s}$ for Kiskdr), which were significantly lower than that recorded with the lowest essential oil treatment $\left(55 \mu \mathrm{g} / \mathrm{cm}^{2}\right.$ ) (Kisumu: $22.06 \mathrm{~s}, p<0.001$; Acerkis: $291.72 \mathrm{~s}, p<0.001$; Kiskdr: $591.63 \mathrm{~s}, p=0)$ (Table 3). At the highest treatment concentration $\left(165 \mu \mathrm{g} / \mathrm{cm}^{2}\right)$, both Acerkis and Kiskdr mosquitoes were quickly knocked down (KDT 50 of $1.71 \mathrm{~s}, p<0.001$ and $2.67 \mathrm{~s}, p<0.001$ respectively) than Kisumu individuals (KDT ${ }_{50}: 3.77 \mathrm{~s}$ ). However, the highest knocked down times values were observed for the Kiskdr (KDT $50>597 \mathrm{~s})$ and Acerkis $\left(K_{50}>291 \mathrm{~s}\right)$ females exposed to the essential oil at $55 \mu \mathrm{g} / \mathrm{cm}^{2}$.

Table 3: Times for 50 and 95\% knockdown of Anopheles gambiae s.s. strains per fragment net treatment. 


\begin{tabular}{|c|c|c|c|c|c|c|c|c|}
\hline Strain & $\begin{array}{l}\text { Essential oil } \\
\text { treatment } \\
\left(\mu \mathrm{g} / \mathrm{cm}^{2}\right)\end{array}$ & $\begin{array}{l}\mathrm{KDT}_{50} \\
\text { (s) }\end{array}$ & $\begin{array}{l}95 \% \mathrm{Cl} \\
\text { [LCL-UCL] }\end{array}$ & $\begin{array}{l}\mathrm{KDT}_{95} \\
\text { (s) }\end{array}$ & $\begin{array}{l}95 \% \mathrm{Cl} \\
\text { [LCL-UCL] }\end{array}$ & $\begin{array}{l}\chi^{2} \text { value of the Pearson } \\
\text { Goodness-of-Fit Test }\end{array}$ & Slope & Intercept \\
\hline \multirow[t]{3}{*}{ Kisumu } & 55 & 22.06 & $\begin{array}{l}{[20.03-} \\
23.82]\end{array}$ & 45.31 & $\begin{array}{l}{[40.51-} \\
53.26]\end{array}$ & 22.17 & 5.26 & -7.07 \\
\hline & 110 & 4.74 & $\begin{array}{l}{[4.54-} \\
4.93]\end{array}$ & 6.27 & $\begin{array}{l}{[5.92-} \\
6.8]\end{array}$ & 2.21 & 13.52 & -9.14 \\
\hline & 165 & 3.77 & $\begin{array}{l}{[3.55-} \\
3.98]\end{array}$ & 5.65 & $\begin{array}{l}{[5.21-} \\
6.36]\end{array}$ & 2.50 & 9.40 & -5.42 \\
\hline \multirow[t]{3}{*}{ Acerkis } & 55 & 291.72 & $\begin{array}{l}{[280.64-} \\
302.38]\end{array}$ & 373.70 & $\begin{array}{l}{[355.49-} \\
400.70]\end{array}$ & 3.62 & 15.29 & -37.69 \\
\hline & 110 & 4.63 & $\begin{array}{l}{[4.44-} \\
4.82]\end{array}$ & 6.17 & $\begin{array}{l}{[5.79-} \\
6.77]\end{array}$ & 2.43 & 23.68 & -15.76 \\
\hline & 165 & 1.71 & $\begin{array}{l}{[1.52-} \\
1.89]\end{array}$ & 3.52 & $\begin{array}{l}{[3.06-} \\
4.29]\end{array}$ & 2.29 & 5.24 & -1.21 \\
\hline \multirow[t]{3}{*}{ Kiskdr } & 55 & 591.63 & $\begin{array}{l}{[576.42-} \\
607.56]\end{array}$ & 813.01 & $\begin{array}{l}{[777.61-} \\
859.02]\end{array}$ & 10.62 & 11.91 & 0.75 \\
\hline & 110 & 197.44 & $\begin{array}{l}{[185.02-} \\
209.26]\end{array}$ & 308.68 & $\begin{array}{l}{[285.79-} \\
341.92]\end{array}$ & 12.28 & 8.47 & -19.45 \\
\hline & 165 & 2.67 & $\begin{array}{l}{[2.46-} \\
2.86]\end{array}$ & 4.40 & $\begin{array}{l}{[3.99-} \\
5.09]\end{array}$ & 1.68 & 7.55 & -3.22 \\
\hline
\end{tabular}

(s): second; $\mathrm{KDT}_{\mathbf{5 0}}$ and $\mathrm{KDT}_{\mathbf{9 5}}$ : Knock-down times for 50 and $95 \%$ of adult mosquitoes after three minutes of exposure to impregnated fragment net with the essential oil in cone test; Cl: Confidence Interval. LCL: Lower confidence limit; UCL: Upper confidence limit. The probit regressions parameters $\left(\chi^{2}\right.$ value of the Pearson Goodness-of-Fit Test, slope and intercept) are indicated.

\section{Induced mortality}

Overall, the three essential oil treatments (concentrations) significantly decreased the survival of all mosquito strains after exposure. For the essential oil coating at $165 \mu \mathrm{g} / \mathrm{cm}^{2}$, the longevity of the three mosquito strains decreased significantly from twenty-four days for Kisumu, twenty-five days for Acerkis and twenty-six days for Kiskdr in control groups to respectively one days for Kisumu $\left(\chi^{2}=99, \mathrm{df}=1, p<0.001\right)$, two days for Acerkis $\left(\chi^{2}=117, \mathrm{df}=1, p<0.001\right)$ and three days for $\operatorname{Kiskdr}\left(\chi^{2}=96.9, \mathrm{df}=1, p\right.$ $<0.001$ ) in exposed groups (Fig 3C). With the net treated at $110 \mu \mathrm{g} / \mathrm{cm}^{2}$, Kisumu females longevity was significantly reduced by 21 days compared to that recorded with the $55 \mu \mathrm{g} / \mathrm{cm}^{2}$ treatment (by 14 days; $\left(\chi^{2}=28.6, \mathrm{df}=1, p<0.001\right.$ ) (Figure 3A and 3B). With each of these two treatments, no significant effect was observed on the longevity of $\operatorname{Kiskdr}\left(\chi^{2}=0, d f=1, p=0.8\right)$.

\section{Discussion}

The increasing number of reports of natural mosquito resistance to the existing synthetic insecticides has strengthened the focus on searching for environmentally-friendly insecticide compounds for vector control strategy. This is a beneficial alternative as essential oils represent a rich source of bioactive compounds that are biodegradable into non-toxic products and due to their natural synergism, they reduce the risk of the development of resistance in the vectors [39]. Besides, essential oils are known as nucleophilic in nature and hinder efficiently with a range of biological processes (metabolic, physiological, biochemical and behavioural) in insects [40-42]. This study is the first report of the larvicidal and adulticidal activity of the $A$. pubescens Benth leaves essential oil on the major African malaria vector An. gambiae s.s. The insecticidal properties of the essential oil of $A$. pubescens leaves were carried out in the laboratory using immature and adult stages of An. gambiae mosquitoes.

The chemical analysis has displayed the presence of 14 compounds. Carvacrol was the major compound representing $51.06 \%$ of the constituents, followed by the thymol acetate $(14.01 \%)$ and $y$-terpinene $(10.60 \%)$. This oil composition is characteristic of the 
carvacrol chemotype. Overall, five (05) different chemotypes were identified from the essential oil of $A$. pubescens aerial part from Togo: i) the thymol chemotype: containing $46.3-58 \%$ of thymol; ii) the carvacrol chemotype: $58.21 \%$ of carvacrol; iii) the carvacrol and thymol chemotype: $41 \%$ of carvacrol and $27 \%$ of thymol, iv) the carvacrol and thymol acetate chemotype: $55.36 \%$ of carvacrol and $35.05 \%$ of thymol acetate, and v) the D-fenchone chemotype: $83.69 \%$ of D-fenchone [43-45]. However, for the same plant material collected in the central regions of Benin, Alitonou et al. [25] identified only the thymol (63\%) and carvacrol (51.1\%) chemotypes. This variability of the chemical composition of essential oils of the same plant material could be due to many factors including: the bioclimate, soil composition, the harvesting period, the geographical location, the degree of maturity of the plant, the seasonal variation and even the plant genetic background [46].

The results from larvae bioassays using the laboratory colonies of An. gambiae showed that the essential oil of $A$. pubescens aerial parts is highly active $\left(\mathrm{LC}_{50}<50 \mathrm{ppm}\right)$ on the specimens of these strains according to the classification of Komalamisra et al. [47]. Both Acerkis and Kiskdr strains larvae were more susceptible to the essential oil $\left(\mathrm{RR}_{50}<1\right)$. These results suggest that the essential oil had a promising larvicidal property with low $\mathrm{LC}_{50}$ values. The significant activity on the resistant strain over the reference susceptible Kisumu mosquitoes indicates that the essential oil does not affect one of the former target sites (Ace- $1^{\mathrm{R}}$ and $\mathrm{Kdr}^{\mathrm{R}}$ (L1014F) alleles) represented in the corresponding strain. Therefore, it could be implied that its mode of action is different from that of pyrethroids, organophosphates and carbamates. However, in the context of the increasing insecticide resistance in natural mosquito populations, it will be interesting to investigate the bioactivity of this essential oil on field-collected larvae and field caught-adults.

Other biological activities of $A$. pubescens essential oil were reported including antioxidant [25, 44], antibacterial [48], but no report was made on its mosquitocidal activity so far. In addition, there is still a lack of information on the bioinsecticidal property of the other plant species belonging to the genus Aeollanthus. However, previous studies have investigated the larvicidal activity of the essential oil of plants belonging to the same family (Lamiaceae). Indeed, Tchoumbougnang et al. [49] showed that Ocimun canum, Ocimum gratissimum and Thymus vulgaris displayed respectively $L_{50}$ value of 201, 180 and $119 \mathrm{ppm}$ on field-collected $A n$. gambiae larvae. These values are higher than those recorded in our study. This variation could be due to the difference in the oils chemical composition and the genetic background of the larvae strains used. Moreover, essential oils from other Lamiaceae species (Plectranthus amboinicus and Plectranthus mollis) were found to be active against Anopheles stephensi larvae with LC $_{50}$ value less than $50 \mathrm{ppm}[50,51]$. These findings suggest that essential oils from Lamiaceae plant species could be a potential source of environmental eco-friendly mosquitocidal agents. In our study, A. pubescens essential oil was dominated by monoterpenes (oxygenated and hydrocarbons) which represented $82.79 \%$ of the oil. Other plants species with similar major constituents have been reported to be active against An. gambiae larvae. Ollengo et al. [52] reported that Clausena anisata containing $56.7 \%$ of monoterpenes revealed a potential larvicidal activity against $A n$. gambiae $\left(\mathrm{LC}_{50}=75.96 \mathrm{ppm}\right)$ [53]. Also, Wangrawa et al. [54] demonstrated that Lantana camara essential oil with $70.5 \%$ of monoterpenes showed differential larval mortalities on both the laboratory and the field strains of An. gambiae. The high proportion of monoterpenes in the essential oil could be correlated to the observed bioactivity. Indeed, many studies reported the larvicidal effect of monoterpenes against mosquitoes strains [55-57]. Therefore, it would be interesting to evaluate further the toxicity of the monoterpenes isolated from $A$. pubescens areal part on mosquito larvae in both laboratory and field trials.

Carvacrol is well known for its larvicidal property against An. stephensi, An. Subpictus, Aedes aegypti, Culex quinquefasciatus and Culex tritaeniorhynchu [58-61]. It will be interesting to evaluate further whether carvacrol, the main compound (51.06\%) found within the monoterpenes in our $A$. pubescens oil extract could be responsible for the observed activity against the An. gambiae larvae.

Essential oils are mixtures of volatile compounds and due to the antagonistic or synergistic phenomena, the bioactivity of the crude oil extract in some cases is lower or higher than those of purified compounds. For instance, Evergetis et al. [62] demonstrated that larvicidal activity of the essential oil of Origanum vulgare ssp against Aedes albopictus $\left(\mathrm{LC}_{50}=30.1 \mathrm{ppm}\right)$ is lower than that of its major component, the pure carvacrol $\left(\mathrm{LC}_{50}=13.1 \mathrm{ppm}\right)$, accounted for $88.7 \%$ of the oil. The same trend was noticed with the leaf essential oil of Coleus aromaticus which displayed lower toxicity than its major component carvacrol against Anopheles stephensi larvae [63]. This open perspectives for further investigations to evaluate the larvicidal efficacy of the carvacrol in comparison to that of the crude oil extract. It is well known that monoterpenes from essential oils could act by absorption through the cuticle, or 
via the respiratory tract or by ingestion via the gastrointestinal tract [64-67]. Besides, several monoterpenes were reported to target primarily the cholinergic, octopamenergic and GABA neurosystems in insects [68]. One or a combination of these mechanisms might be the pathway of mortality induction by the A. pubscens oil. In this study, the reference resistant strain Acerkis larvae haboring ace- $1^{R}$ allele coding for the insensitive acetylcholinesterase enzyme was the most susceptible to our essential oil. This indicates that the essential oil overcomes the target site modification resistance mechanism and therefore appears as a hopeful alternative tool for vector control programs.

Among the vector life-history traits, mosquito survival is strongly associated with the malaria transmission intensity [69]. Thus, this study also investigated the effect of exposure to various doses of $A$. pubescens oil on adults $A n$. gambiae survival. The $A$. pubescens essential oil reduced significantly the lifespan of the three mosquitoes strains exposed to the fragment net at 165 $\mu \mathrm{g} / \mathrm{cm}^{2}$. None of the three mosquito strains was able to survive after 72 hours. This observation suggests that even the resistance mosquitoes (Acerkis and Kiskdr) could not survive long enough to allow the extrinsic incubation period of the Plasmodium parasites if they ingested a gametocyte infected blood meal. Overall, the drastic reduction in daily survival of mosquitoes observed with the oil treatment at $165 \mu \mathrm{g} / \mathrm{cm}^{2}$ would contribute to a reduction in vectorial capacity in a typical endemic setting and therefore will lead to a reduction in parasite transmission according to the Ross-MacDonald model [70]. This is a promising finding for the management of the resistant malaria-transmitting vectors. Spray-type solution formulations could be made towards the development of botanical insecticides for the use of an integrated approach with the existing conventional vector control strategies. However, the results were obtained using mosquito strains in which only one resistance mechanism is present. It will be interesting to evaluate further the survivorship of the natural mosquito populations where several resistance mechanisms could coexist. The susceptibility of Plasmodium infection following essential oil exposure is also another promising parameter to be evaluated.

During the experiment, we observed that the legs of mosquitoes were detached from their bodies when exposed to the net coated at $165 \mathrm{\mu g} / \mathrm{cm}^{2}$. To our knowledge, this phenomenon has not been observed yet. However, such mechanism is so far unexplored. Possible neurotoxicity in insects could have been easily overlooked. Thus, investigations around the mechanisms used by this compound is urgently sought. The mosquito legs loss suggests that the essential oil could interfere with the insect locomotor system and even the nervous system leading to the death in the following days.

At the doses 55 and $110 \mu \mathrm{g} / \mathrm{cm}^{2}$ of the essential oil, the lifespan of mosquitoes is fourteen (14) days maximum for both resistant Acerkis and Kiskdr strains. During this time period, mosquitoes might still be able to reproduce. Therefore, further studies are needed to assess the blood-feeding success, the fecundity and the fertility of mosquitoes following exposure. This could lead to highlight putative detrimental effects of the essential oil exposure that could also hamper the vectorial competence of the mosquitoes.

\section{Conclusion}

The present study paves the way to develop a new and safer natural insecticide against malaria mosquito vectors. The $A$. pubescens Benth essential oil is proved to be an efficient larvicide and adulticide against the malaria vector An. gambiae. This opens the perspectives for implementing sustainable control of mosquito populations that are resistant to the current existing synthetic insecticides. The larval and adult vector control with the essential oil could be considered in an integrated fashion to the existing malaria control strategies. Further studies are needed to help in designing $A$. pubescens essential oil formulation that would potentially increase its efficacy on An. gambiae and its cost-effectiveness.

\section{Declarations}

\section{Ethics approval and consent to participate}

Not applicable

\section{Consent for publication}

Not applicable. 
Availability of data and materials

All data generated or analysed during this study are included in this published article and its supplementary information files.

\section{Competing interests}

The authors declare that they have no competing interests.

\section{Funding}

LSD is funded by Welcome Trust (grant $\left.N^{\circ} 109917 / Z / 15 / Z\right)$. The funder played no role in the study design, data collection and analysis, decision to publish, or preparation of the manuscript.

\section{Acknowledgments}

The authors thank Geraldine Foster from Liverpool School of Tropical Medicine (LSTM) for the material support. We are grateful to Ms Marie Joelle Fanou for her assistance in insectary work; Mrs Laurette Djossou for her help during data acquisition; Mrs Emilienne Fiogbe and Mr Jean-Louis Amoussou for their helpful proofreading of the manuscript.

\section{Author Contributions}

Conceived and designed the experiments: Roméo Barnabé Bohounton, Luc Salako Djogbénou, Pierre Villeneuve, Fidèle Paul Tchobo.

Performed the experiments: Roméo Barnabé Bohounton, Pierre Marie Sovegnon, Bruno Barea.

Data analysis: Roméo Barnabé Bohounton, Oswald Yédjinnavênan Djihinto, Oronce Sedjro-Ludolphe Dedome.

Writing - original draft: Roméo Barnabé Bohounton, Oswald Yédjinnavênan Djihinto.

Writing - review \& editing: Roméo Barnabé Bohounton, Oswald Yédjinnavênan Djihinto, Aristide Adomou, Luc Salako Djogbénou, Fidèle Paul Tchobo.

\section{References}

1. Leitner WW, Wali T, Kincaid R, Costero-Saint Denis A. Arthropod Vectors and Disease Transmission: Translational Aspects. PLoS Negl Trop Dis. 2015;9. doi:10.1371/journal.pntd.0004107

2. World Health Organization. Vector-borne diseases. 2020 [cited 26 Aug 2020]. Available: https://www.who.int/news-room/factsheets/detail/vector-borne-diseases

3. Karunamoorthi K. Global malaria eradication: is it still achievable and practicable? http://www.ncbi.nlm.nih.gov/nlmcatalog/101566132. In: Peterson AM, Calamandrei GE, editors. Malaria: etiology, pathogenesis and treatments. http://www.ncbi.nIm.nih.gov/nlmcatalog/101566132. New York: Nova Science Publishers; 2012.

4. World Health Organization. World malaria report 2019. 2019. Available: https://www.who.int/publications/i/item/worldmalaria-report-2019

5. Institute of Medicine (US) Committee on the Economics of Antimalarial Drugs, Arrow KJ, Panosian C, Gelband H. The Parasite, the Mosquito, and the Disease. Saving Lives, Buying Time: Economics of Malaria Drugs in an Age of Resistance. National Academies Press (US); 2004. Available: https://www.ncbi.nlm.nih.gov/books/NBK215619/

6. Karunamoorthi K. Vector control: a cornerstone in the malaria elimination campaign. Clin Microbiol Infect. 2011;17: 16081616. doi:10.1111/j.1469-0691.2011.03664.x

7. World Health Organization. WHO Recommended Insecticides for Indoor Residual Spraying against Malaria Vectors. 21 Sep 2018 [cited 27 Aug 2020]. Available: https://www.who.int/neglected_diseases/vector_ecology/vectorcontrol/Insecticides_IRS_22_September_2018.pdf?ua=1 
8. Nogueira Barradas T, Perdiz Senna J, Ricci Júnior E, Regina Elias Mansur C. Polymer-based Drug Delivery Systems Applied to Insects Repellents Devices: A Review. CDD. 2016;13: 221-235. doi:10.2174/1567201813666151207110515

9. Ranson H, Abdallah H, Badolo A, Guelbeogo WM, Kerah-Hinzoumbé C, Yangalbé-Kalnoné E, et al. Insecticide resistance in Anopheles gambiae: data from the first year of a multi-country study highlight the extent of the problem. Malaria Journal. 2009;8: 299. doi:10.1186/1475-2875-8-299

10. Mouhamadou CS, de Souza SS, Fodjo BK, Zoh MG, Bli NK, Koudou BG. Evidence of insecticide resistance selection in wild Anopheles coluzzii mosquitoes due to agricultural pesticide use. Infectious Diseases of Poverty. 2019;8: 64. doi:10.1186/s40249-019-0572-2

11. Newsom LD. Consequences of Insecticide Use on Nontarget Organisms. Annual Review of Entomology. 1967;12: 257-286. doi:10.1146/annurev.en.12.010167.001353

12. Smith TM, Stratton GW. Effects of synthetic pyrethroid insecticides on nontarget organisms. In: Gunther FA, editor. Residue Reviews. New York, NY: Springer New York; 1986. pp. 93-120. doi:10.1007/978-1-4612-4934-4_4

13. Ware GW. Effects of pesticides on nontarget organisms. In: Gunther FA, Gunther JD, editors. Residue Reviews. New York, NY: Springer New York; 1980. pp. 173-201. doi:10.1007/978-1-4612-6107-0_9

14. Mahmood I, Imadi SR, Shazadi K, Gul A, Hakeem KR. Effects of Pesticides on Environment. In: Hakeem KR, Akhtar MS, Abdullah SNA, editors. Plant, Soil and Microbes. Cham: Springer International Publishing; 2016. pp. 253-269. doi:10.1007/978-3-319-27455-3_13

15. Rout S, Mahapatra RK. Plasmodium falciparum: Multidrug resistance. Chem Biol Drug Des. 2019;93: 737-759. doi:10.1111/cbdd.13484

16. Benelli G, Jeffries CL, Walker T. Biological Control of Mosquito Vectors: Past, Present, and Future. Insects. 2016;7. doi:10.3390/insects7040052

17. Shaalan EA-S, Canyon D, Younes MWF, Abdel-Wahab H, Mansour A-H. A review of botanical phytochemicals with mosquitocidal potential. Environment International. 2005;31: 1149-1166. doi:10.1016/j.envint.2005.03.003

18. Thomson M, Vijan A. Environmental Friendly Bio-pesticides: A Review. Research \& Reviews: Journal of Agriculture and Allied Sciences. 2016;5: 31-39.

19. Hermans $M$, Akoègninou $A$, van der Maesen J. Medicinal plants used to treat malaria in Southern Benin. Econ Bot. 2004;58: S239-S252. doi:10.1663/0013-0001(2004)58[S239:MPUTTM]2.0.C0;2

20. Guevara N, Wotto V, Jean-Pierre N, Avlessi F, Martin A, Sohounhloue D. Insecticidal activities of essential oils extracted from three species of poaceae on Anopheles gambiaespp, major vector of malaria. Scientific Study \& Research Chemistry \& Chemical Engineering, Biotechnology, Food Industry. 2010;11.

21. Bossou AD, Mangelinckx S, Yedomonhan H, Boko PM, Akogbeto MC, De Kimpe N, et al. Chemical composition and insecticidal activity of plant essential oils from Benin against Anopheles gambiae (Giles). Parasites Vectors. 2013;6: 337. doi:10.1186/1756-3305-6-337

22. Akpo AA, Chougourou DC, Djènontin A, Dossou J, Anagonou R, Akogbéto M. Etude De L'efficacité Du Cashew Nut Shell Liquid (CNSL) De Anacardium Occidentale L. Extrait À Froid Sur Le Contrôle De Anopheles Gambiae S.L Résistant Aux Pyréthrinoïdes. European Scientific Journal, ESJ. 2017;13: 249-249. doi:10.19044/esj.2017.v13n24p249

23. Adjanohoun É, Agence de Coopération Culturelle et Technique, editors. Contribution aux études ethnobotaniques et floristiques au Togo. Paris: Agence de Coopération Culturelle et Technique; 1987.

24. Kafoutchoni KM, Idohou R, Egeru A, Salako KV, Agbangla C, Adomou AC, et al. Species richness, cultural importance, and prioritization of wild spices for conservation in the Sudano-Guinean zone of Benin (West Africa). J Ethnobiol Ethnomed. 2018;14. doi:10.1186/s13002-018-0267-y

25. Alitonou G, Tchobo F, Avlessi F, Sohounhloue DK, Menut C. Aeollanthus pubescens Benth. from Benin: A Potential Source of Essential Oil with High Antiradical Efficiency. Journal of Essential Oil Bearing Plants. 2013;16: 308-314. doi:10.1080/0972060X.2013.813203

26. Adams RP, Adams RP. Identification of essential oil components by gas chromatography/quadrupole mass spectroscopy. Carol Stream, III.: Allured Pub. Corp.; 2004. 
27. Shute GT. A Method of Maintaining Colonies of East African Strains of Anopheles Gambiae. Annals of Tropical Medicine \& Parasitology. 1956;50: 92-94. doi:10.1080/00034983.1956.11685743

28. Djogbénou L, Weill M, Hougard JM, Raymond M, Akogbéto M, Chandre F. Characterization of insensitive acetylcholinesterase (ace-1R) in Anopheles gambiae (Diptera: Culicidae): resistance levels and dominance. J Med Entomol. 2007;44: 805-810. doi:10.1603/0022-2585(2007)44[805:coiaai]2.0.co;2

29. Alout H, Ndam NT, Sandeu MM, Djégbe I, Chandre F, Dabiré RK, et al. Insecticide Resistance Alleles Affect Vector Competence of Anopheles gambiae s.s. for Plasmodium falciparum Field Isolates. PLOS ONE. 2013;8: e63849. doi:10.1371/journal.pone.0063849

30. World Health Organization. Guidelines for laboratory and field testing of mosquito larvicides. 2005 [cited 28 Aug 2020]. Available: https://apps.who.int/iris/handle/10665/69101

31. WHO. Guidelines for laboratory and field-testing of long-lasting insecticide nets. Dr R. Yadav/WHOPES, editor. 2013.

32. Milesi P, Labbé P. BioRssay: A R Script for Bioassay Analyses v. 6.2. Montpellier, France; 2015. Available: http://wwwisemunivmontp2.fr/recherche/equipes/genomiquedeladaptation/personnel/labbe-pierrick/

33. R Core Team. R: A language and environment for statistical computing. Vienna, Austria: R Foundation for Statistical Computing; 2017. Available: https://www.R-project.org/

34. Mazzarri MB, Georghiou GP. Characterization of resistance to organophosphate, carbamate, and pyrethroid insecticides in field populations of Aedes aegypti from Venezuela. J Am Mosq Control Assoc. 1995;11: 315-322.

35. Bisset JA, Rodríguez MM, Ricardo Y, Ranson H, Pérez O, Moya M, et al. Temephos resistance and esterase activity in the mosquito Aedes aegypti in Havana, Cuba increased dramatically between 2006 and 2008. Medical and Veterinary Entomology. 2011;25: 233-239. doi:https://doi.org/10.1111/j.1365-2915.2011.00959.x

36. Hlina BL. Package "ecotox." Cambridge [Eng.]: University Press; 2020.

37. Finney DJ, Tattersfield F. Review of Probit Analysis: A Statistical Treatment of the Sigmoid Response Curve. Journal of the Royal Statistical Society. 1947;110: 263-266. doi:10.2307/2981407

38. Wheeler MW, Park RM, Bailer AJ. Comparing median lethal concentration values using confidence interval overlap or ratio tests. Environmental Toxicology and Chemistry. 2006;25: 1441-1444. doi:https://doi.org/10.1897/05-320R.1

39. Park H-M, Kim J, Chang K-S, Kim B-S, Yang Y-J, Kim G-H, et al. Larvicidal activity of Myrtaceae essential oils and their components against Aedes aegypti, acute toxicity on Daphnia magna, and aqueous residue. J Med Entomol. 2011;48: 405410. doi:10.1603/me10108

40. Benelli G. Plant-borne ovicides in the fight against mosquito vectors of medical and veterinary importance: a systematic review. Parasitol Res. 2015;114: 3201-3212. doi:10.1007/s00436-015-4656-z

41. Pavela R. Essential oils for the development of eco-friendly mosquito larvicides: A review. Industrial Crops and Products. 2015;76: 174-187. doi:10.1016/j.indcrop.2015.06.050

42. Brattsten LB. Cytochrome P-450 Involvement in the Interactions Between Plant Terpenes and Insect Herbivores. Plant Resistance to Insects. AMERICAN CHEMICAL SOCIETY; 1983. pp. 173-195. doi:10.1021/bk-1983-0208.ch010

43. Sanda K, Koba K, Walla BA, Akpagana K, Garneau F-X, Gagnon H, et al. Aeollanthus pubescens Benth. A Potential Source of Thymol-rich Essential Oil. Journal of Essential Oil Research. 1999;11: 257-258. doi:10.1080/10412905.1999.9701126

44. Agbodan KA, Dotse K, Koumaglo KH. Activités antioxydantes des huiles essentielles de trois plantes aromatiques acclimatées au Togo. International Journal of Biological and Chemical Sciences. 2014;8: 1103-1110. doi:10.4314/ijbcs.v8i3.23

45. Koba K, Sanda K, Raynaud C, Millet J, Chaumont J-P. Composition chimique des huiles essentielles d'Aeollanthus pubescens Benth. acclimatée au Togo. Comptes Rendus Chimie. 2004;7: 1107-1111. doi:10.1016/j.crci.2003.12.038

46. Dhifi W, Bellili S, Jazi S, Bahloul N, Mnif W. Essential Oils' Chemical Characterization and Investigation of Some Biological Activities: A Critical Review. Medicines (Basel). 2016;3. doi:10.3390/medicines3040025

47. Komalamisra N, Trongtokit Y, Rongsriyam Y, Apiwathnasorn C. Screening for larvicidal activity in some Thai plants against four mosquito vector species. Southeast Asian J Trop Med Public Health. 2005;36: 1412-1422.

48. Sessou P, Yaovi BA, Yovo M, Gamedjo J, Dossa F, Aguidissou ON, et al. Phytochemistry and antibacterial activity of plants extracts compared with two commercial antibiotics against $\mathrm{E}$ coli responsible for avian colibacillosis in Benin. ijpm. 2018;10: 
168. doi:10.5138/09750185.2259

49. Tchoumbougnang F, Dongmo PMJ, Lambert M, Mbanjo EGN, Fotso GBT, Henri P, et al. Activité larvicide sur Anopheles gambiae Giles et composition chimique des huiles essentielles extraites de quatre plantes cultivées au Cameroun. Biotechnol Agron Soc Environ. 2009; 8.

50. Senthilkumar A, Venkatesalu V. Chemical composition and larvicidal activity of the essential oil of Plectranthus amboinicus (Lour.) Spreng against Anopheles stephensi: a malarial vector mosquito. Parasitol Res. 2010;107: 1275-1278. doi:10.1007/s00436-010-1996-6

51. Kulkarni RR, Pawar PV, Joseph MP, Akulwad AK, Sen A, Joshi SP. Lavandula gibsoni and Plectranthus mollis essential oils: chemical analysis and insect control activities against Aedes aegypti, Anopheles sfttephensi and Culex quinquefasciatus. J Pest Sci. 2013;86: 713-718. doi:10.1007/s10340-013-0502-1

52. Ollengo MA, Vulule JM, Matasyoh JC. Larvicidal Activity of Clausena Anisata Oils and Extracts Anopheles Gambie Larvea. International Journal of Research in Pharmacy and Pharmaceutical Sciences. 2016;1: 13-20.

53. Ollengo MA. Larvicidal Activity of Clausena Anisata Oils and Extracts Anopheles Gambie Larvea. [cited 22 Sep 2020]. Available:

https://www.academia.edu/29553647/Larvicidal_Activity_of_Clausena_Anisata_Oils_and_Extracts_Anopheles_Gambie_Larvea

54. Wangrawa DW, Badolo A, Ilboudo Z, Guelbéogo WM, Kiendrébeogo M, Nébié RCH, et al. Insecticidal Activity of Local Plants Essential Oils Against Laboratory and Field Strains of Anopheles gambiae s. I. (Diptera: Culicidae) From Burkina Faso. Journal of Economic Entomology. 2018 [cited 6 Oct 2020]. doi:10.1093/jee/toy276

55. Sanei-Dehkordi A, Soleimani-Ahmadi M, Akbarzadeh K, Abadi YS, Paksa A, Gorouhi MA, et al. Chemical Composition and Mosquito Larvicidal Properties of Essential Oil from Leaves of an Iranian Indigenous Plant Zhumeria majdae. Journal of Essential Oil Bearing Plants. 2016;19: 1454-1461. doi:10.1080/0972060X.2016.1222886

56. Govindarajan M, Benelli G. a-Humulene and $\beta$-elemene from Syzygium zeylanicum (Myrtaceae) essential oil: highly effective and eco-friendly larvicides against Anopheles subpictus, Aedes albopictus, and Culex tritaeniorhynchus (Diptera: Culicidae). Parasitol Res. 2016;115: 2771-2778. doi:10.1007/s00436-016-5025-2

57. Kweka EJ, Lima TC, Marciale CM, de Sousa DP. Larvicidal efficacy of monoterpenes against the larvae of Anopheles gambiae. Asian Pacific Journal of Tropical Biomedicine. 2016;6: 290-294. doi:10.1016/j.apjtb.2016.03.001

58. Govindarajan M, Rajeswary M, Hoti SL, Benelli G. Larvicidal potential of carvacrol and terpinen-4-ol from the essential oil of Origanum vulgare (Lamiaceae) against Anopheles stephensi, Anopheles subpictus, Culex quinquefasciatus and Culex tritaeniorhynchus (Diptera: Culicidae). Research in Veterinary Science. 2016;104: 77-82. doi:10.1016/j.rvsc.2015.11.011

59. Lima MAA, Oliveira FFM de, Gomes GA, Lavor PL, Gilv, Santiago ete MP, et al. Evaluation of larvicidal activity of the essential oils of plants species from Brazil against Aedes aegypti (Diptera: Culicidae). AJB. 2011;10: 11716-11720. doi:10.5897/AJB.9000241

60. Santos SRL, Silva VB, Melo MA, Barbosa JDF, Santos RLC, de Sousa DP, et al. Toxic Effects on and Structure-Toxicity Relationships of Phenylpropanoids, Terpenes, and Related Compounds in Aedes aegypti Larvae. Vector-Borne and Zoonotic Diseases. 2010;10: 1049-1054. doi:10.1089/vbz.2009.0158

61. Silva WJ, Dória GAA, Maia RT, Nunes RS, Carvalho GA, Blank AF, et al. Effects of essential oils on Aedes aegypti larvae: Alternatives to environmentally safe insecticides. Bioresource Technology. 2008;99: 3251-3255. doi:10.1016/j.biortech.2007.05.064

62. Evergetis E, Bellini R, Balatsos G, Michaelakis A, Carrieri M, Veronesi R, et al. From Bio-Prospecting to Field Assessment: The Case of Carvacrol Rich Essential Oil as a Potent Mosquito Larvicidal and Repellent Agent. Front Ecol Evol. 2018;6. doi:10.3389/fevo.2018.00204

63. Govindaraju S, Karthik C, Arulselvi PI. Evaluation of chemical composition and larvicidal activity of Coleus aromaticus essential oil, its major compound carvacrol against Aedes aegypti, Culex quinquefasciatus and Anopheles stephensi (Diptera: Culicidae). Int J Mosq Res. 2016;3: 06-11.

64. Cantrell CL, Pridgeon JW, Fronczek FR, Becnel JJ. Structure-Activity Relationship Studies on Derivatives of Eudesmanolides from Inula helenium as Toxicants against Aedes aegypti Larvae and Adults. Chemistry \& Biodiversity. 2010;7: 1681-1697. doi:10.1002/cbdv.201000031

Page $14 / 17$ 
65. Gnankiné O, Bassolé IHN. Essential Oils as an Alternative to Pyrethroids' Resistance against Anopheles Species Complex Giles (Diptera: Culicidae). Molecules. 2017;22. doi:10.3390/molecules22101321

66. Prates HT, Santos JP, Waquil JM, Fabris JD, Oliveira AB, Foster JE. Insecticidal activity of monoterpenes against Rhyzopertha dominica (F.) and Tribolium castaneum (Herbst). Journal of Stored Products Research. 1998;34: 243-249.

doi:10.1016/S0022-474X(98)00005-8

67. Regnault-Roger C. The potential of botanical essential oils for insect pest control. Integrated Pest Management Reviews. 1997;2: 25-34. doi:10.1023/A:1018472227889

68. Rattan RS. Mechanism of action of insecticidal secondary metabolites of plant origin. Crop Protection. 2010;29: 913-920. doi:10.1016/j.cropro.2010.05.008

69. Ferguson H, Maire N, Takken W, Lyimo I, Briet O, Lindsay S, et al. Selection of mosquito life-histories: A hidden weapon against malaria? Malaria journal. 2012;11: 106. doi:10.1186/1475-2875-11-106

70. Smith DL, Battle KE, Hay SI, Barker CM, Scott TW, McKenzie FE. Ross, Macdonald, and a Theory for the Dynamics and Control of Mosquito-Transmitted Pathogens. PLOS Pathogens. 2012;8: e1002588. doi:10.1371/journal.ppat.1002588

\section{Figures}

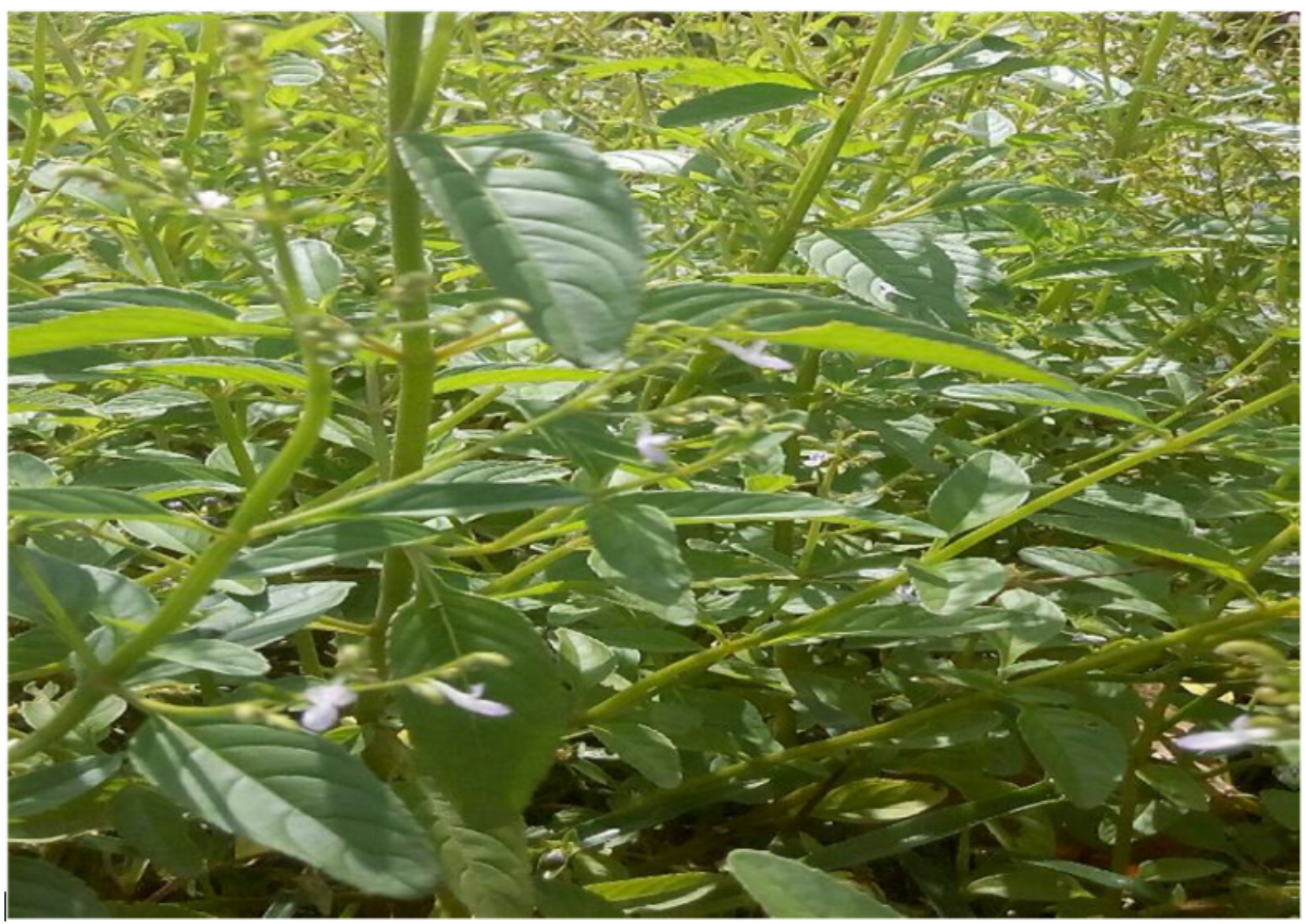

\section{Figure 1}

Areal part of Aeollanthus pubescens Benth harvested in Benin. 


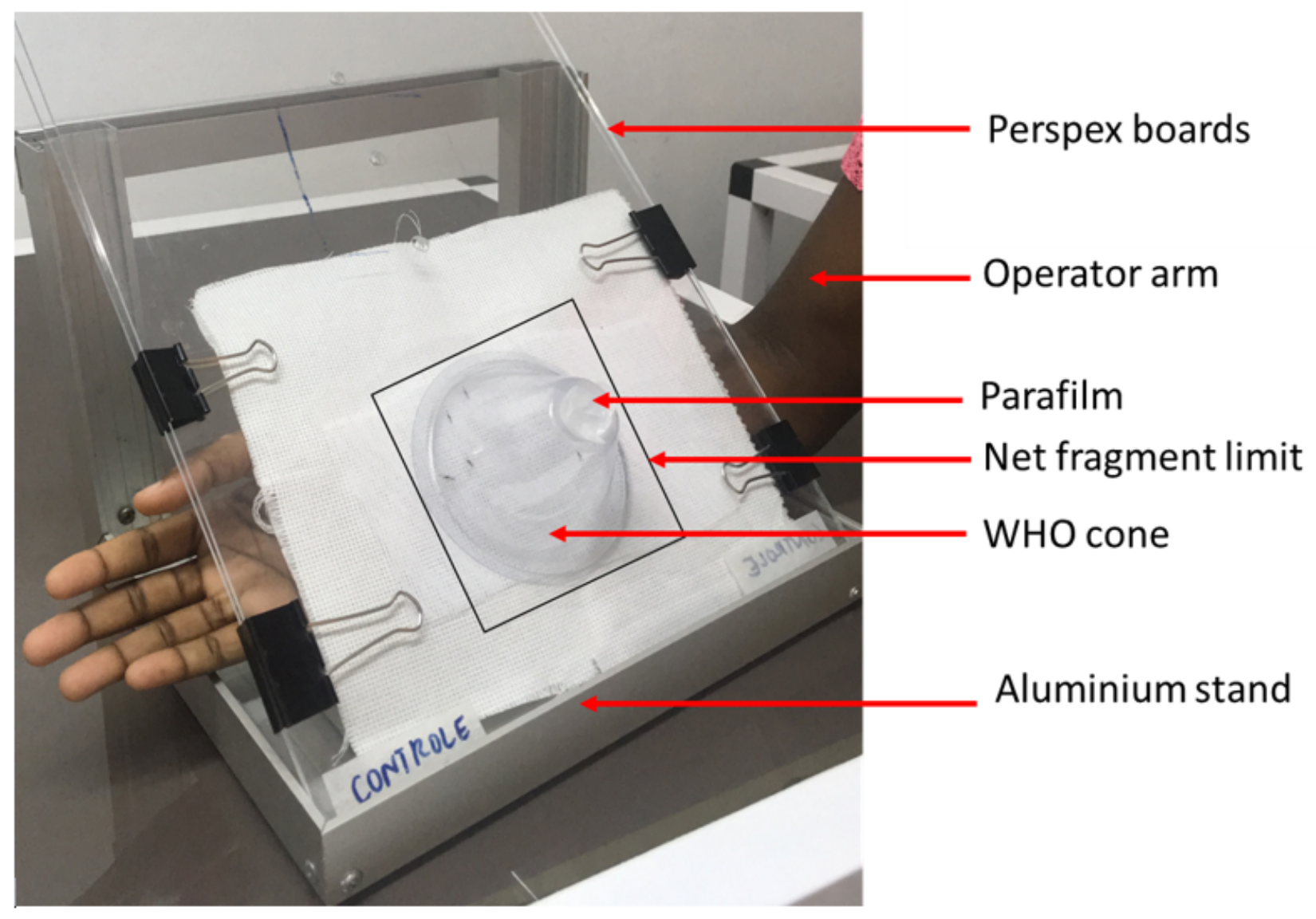

Figure 2

Cone test equipment.
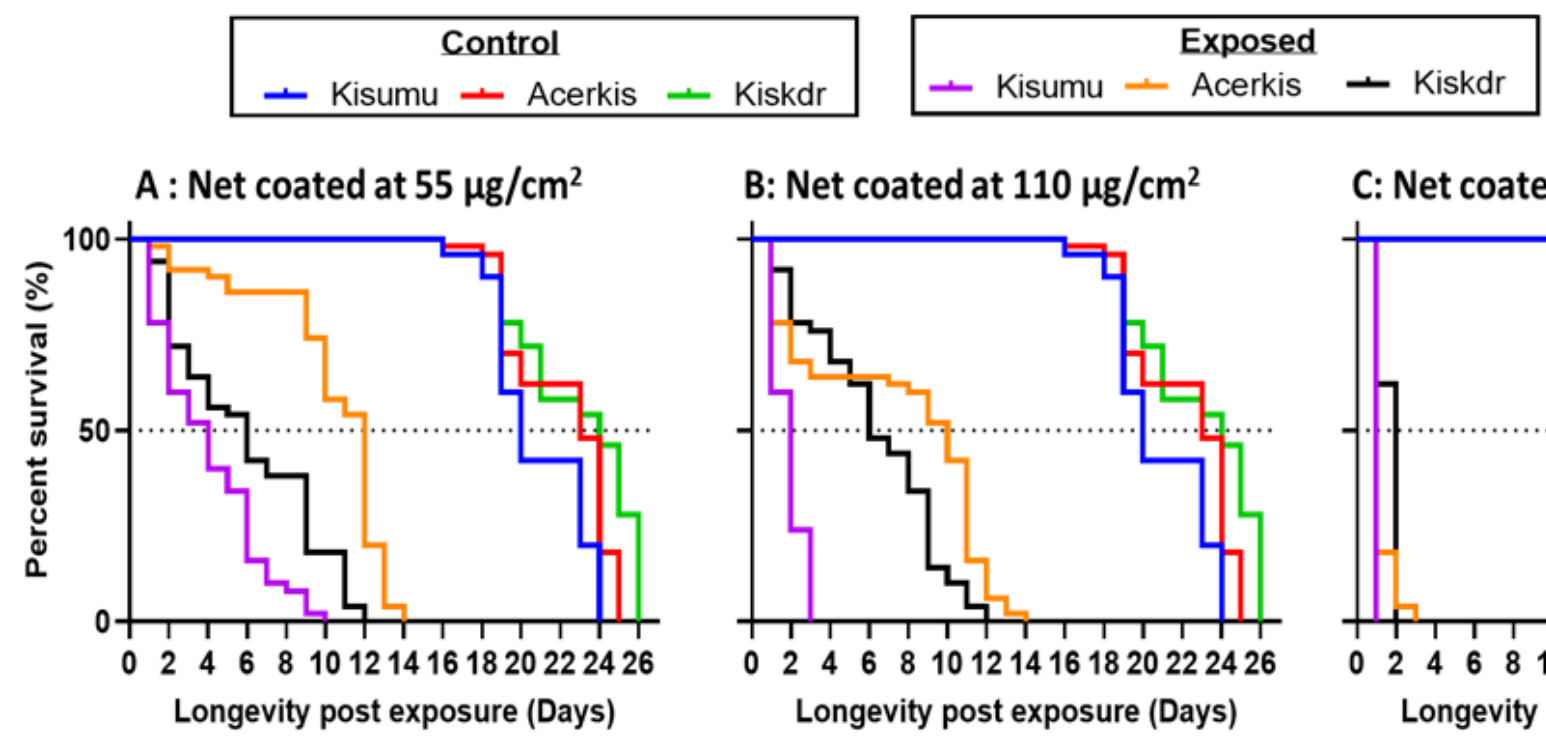

C: Net coated at $165 \mu \mathrm{g} / \mathrm{cm}^{2}$

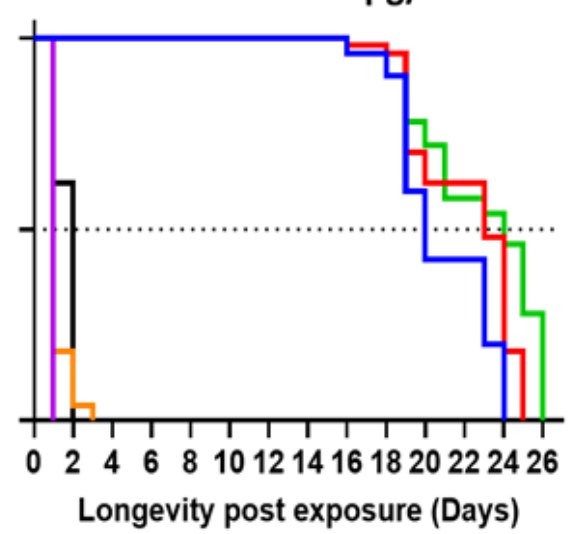

Figure 3

Survivorship of adult female mosquitoes post exposure. Each of mosquito strains was followed up after exposure to fragment net impregnated with the A. pubescens essential oil at $55 \mu \mathrm{g} / \mathrm{cm} 2$ (A); $110 \mu \mathrm{g} / \mathrm{cm} 2$ (B) and $165 \mu \mathrm{g} / \mathrm{cm} 2$ (C). 


\section{Supplementary Files}

This is a list of supplementary files associated with this preprint. Click to download.

- Graphicalabstract.jpg

- Supplementaryinformation.xlsx 